\title{
Community Pharmacists' Knowledge, Practices and Perceptions on Antibiotic Use and Resistance: A Cross-Sectional, Self-Administered Questionnaire Survey, in Guediawaye and Pikine, Senegal
}

\author{
Oumar Bassoum1,2*, Awa Ba-Diallo3, Ndèye Marème Sougou1,2, \\ Mamadou Makhtar Mbacke Lèye ${ }^{1,2}$, Mayassine Diongue ${ }^{1,2}$, Ndèye Fatou Cissé4, \\ Adama Faye1,2, Ibrahima Seck ${ }^{1,2}$, Djibril Fall4, Anta Tal-Dia1,2 \\ ${ }^{1}$ Department of Public Health and Preventive Medicine, Faculty of Medicine, Pharmacy and Odontology, \\ University Cheikh Anta Diop, Dakar, Senegal \\ ${ }^{2}$ Institute of Health and Development, University Cheikh Anta Diop, Dakar, Senegal \\ ${ }^{3}$ Laboratory of Bacteriology and Virology, National University Hospital Center, Dakar, Senegal \\ ${ }^{4}$ Laboratory of Therapeutic and Organic Chemistry, Faculty of Medicine, Pharmacy and Odontology, University \\ Cheikh Anta Diop, Dakar, Senegal \\ Email: `bassoum.oumar@gmail.com, *oumar.bassoum@ucad.edu.sn
}

How to cite this paper: Bassoum, O., Ba-Diallo, A., Sougou, N.M., Lèye, M.M.M., Diongue, M., Cissé, N.F., Faye, A., Seck, I., Fall, D. and Tal-Dia, A. (2019) Community Pharmacists' Knowledge, Practices and Perceptions on Antibiotic Use and Resistance: A Cross-Sectional, Self-Administered Questionnaire Survey, in Guediawaye and Pikine, Senegal. Open Journal of Epidemiology, 9, 289-308.

https://doi.org/10.4236/ojepi.2019.94021

Received: February 9, 2019

Accepted: November 1, 2019

Published: November 4, 2019

Copyright $\odot 2019$ by author(s) and Scientific Research Publishing Inc. This work is licensed under the Creative Commons Attribution International License (CC BY 4.0). http://creativecommons.org/licenses/by/4.0/

\section{Open Access}

\begin{abstract}
Background: Antibiotic resistance is a threat to global health. Community pharmacists are among the most accessible health professionals. Therefore, their role in improving antibiotic use and subsequently in fighting resistance is crucial. The objective of this study was to evaluate community pharmacists' knowledge, practices and perceptions on antibiotic use and resistance. Methods: We conducted a cross-sectional study in community pharmacies located in the departments of Guediawaye and Pikine, Senegal. The study took place between November 2017 and February 2018. A total of 121 community pharmacies were located. In each of them, we planned to include one pharmacist. A self-administered questionnaire was used. The data were analyzed using Epi Info 7. The analysis was descriptive. Variables were expressed as number (n) and percentage (\%). Results: The response rate was $75.2 \%$. The majority mistakenly thought that antibiotics are always effective against sore throat $(64.8 \%)$, bronchitis (51.6\%), paronychia (72.5\%) and dental caries (65.9\%). Most respondents knew that self-medication (96.7\%), poor treatment compliance $(94.5 \%)$, inappropriate antibiotic dispensing (79.1\%), inappropriate antibiotic prescribing $(85.7 \%)$ were causes of resistance. Further,
\end{abstract}


causes such as poor hand hygiene and lack of immunization were cited by $9.9 \%$ and $6.6 \%$ of participants. Moreover, $25.2 \%$ knew that third-generation cephalosporins, macrolides and quinolones are critically important antibiotics. In addition, $96.7 \%$ and $90.2 \%$ said to dispense antibiotics without a prescription and to contact prescribers in case of doubt about the reliability of an antibiotic prescription, respectively. The majority was of the opinion that some antibiotic prescriptions were inadequate $(29.7 \%)$ and that the consumption of antibiotics was high (92.3\%). Conclusion: This study showed a lack of knowledge among community pharmacists practicing in Guediawaye and $\mathrm{Pi}$ kine towards antibiotic use and resistance. Therefore, it is necessary to sensitize them. Further studies should be conducted to better understand the beliefs and behavior of community pharmacists regarding antibiotic use and resistance.

\section{Keywords}

Community Pharmacists, Knowledge, Practices, Senegal, Antibiotic

Resistance

\section{Introduction}

Antibiotic resistance is one of the biggest threats to public health [1]. According to the first World Health Organization (WHO) report on antimicrobial resistance (AMR), resistant bacteria have spread to all regions of the world [2]. This report highlights high rates of resistance to antibiotics commonly used against not only healthcare-associated infections but also community-acquired infections [2]. In the United States, the Centers for Disease Control and Prevention (CDC) estimate that resistant infections occur in nearly two million people and classified the threat into three categories [1]: urgent threat (e.g. Clostridium difficile, Carbapenem-resistant Enterobacteriaceae), serious threat (e.g. Multidrug-resistant Acinetobacter, Drug-resistant Campylobacter, Drug-resistant tuberculosis), and threatening threat (e.g. Vancomycin-resistant Staphylococcus aureus, Erythromycin-resistant Group A Streptococcus).

In Africa, the magnitude of the problem is not very well known due to insufficient data [2]. However, antibiotic resistance concerns several diseases including tuberculosis, typhoid, cholera, meningitis, gonorrhea and dysentery [3]. The WHO report shows that Escherichia coli is highly resistant to third-generation cephalosporins and fluoroquinolones and that $80 \%$ of Staphylococcus aureus infections are resistant to methicillin [2]. Cases of carbapenem resistance in enterobacteriaceae are reported in West Africa with prevalence ranging from 10 to $30 \%[4]$.

In Senegal, a study found high levels of resistance to tetracyclines (95\%), co-trimoxazole (60\%) and ampicillin (55\%) [5].

Antibiotic resistance is a natural process [6]. However, it is strongly associated with several factors. The first of these is the overuse of antibiotics [6]. In devel- 
oping countries, this phenomenon is favored by inappropriate prescriptions [4]. Worldwide, more than $50 \%$ of antibiotic prescriptions are inappropriate or incorrectly used [1]. Added to this is the over-the-counter sale of antibiotics in both community pharmacies and popular markets [6] [7].

The use of counterfeit or substandard antibiotics also contributes to the emergence of resistance [8]. In Africa, more than $60 \%$ of antimicrobials such as penicillins and tetracyclines are of low quality [8].

In the livestock and agriculture sectors, the overuse of antibiotics generates resistant strains that are transmitted to humans via the food chain [6].

The consequences of antibiotic resistance are alarming. If nothing is done, they will be felt in all regions of the world [9]. Clinically, antibiotic-resistant infections will result in high mortality and morbidity [6] [9]. In the United States, they cause 23,000 deaths each year [1]. In addition, they lead to the use of broad-spectrum antibiotics that contribute to the destruction of normal microbial flora [10].

Economically, according to the World Bank, by 2050, AMR, and particularly antibiotic resistance, could have an impact comparable to the 2008 financial crisis. In developing countries, it could push 28 million people into poverty and threaten the achievement of the Sustainable Development Goals [8].

Faced with this alarming situation, several initiatives are taken. A global action plan against RAM is developed by the WHO. This plan is supported by the World Organization for Animal Health (OIE) and the Food and Agriculture Organization (FAO) according to the One Health approach. The latter aims to promote the rational use of antibiotics in both human medicine and veterinary medicine. The goals of the plan focus on educating health professionals and the general public, monitoring AMR, the rational use of antibiotics and the discovery of new drugs, vaccines and diagnostic tools [11].

The European Union has also developed an action plan on AMR. This plan pays particular attention to developing countries. The commission intends to contribute to the reduction of AMR in these countries. It intends to provide support in the areas of immunization, food safety and animal health [12].

Some antibiotic classes are categorized based on their critical importance for human medicine or their potential to select resistance. These include macrolides [13], third-generation cephalosporins [13] [14], quinolones [13] [14] and amoxicillin/clavulanic acid [14].

In Africa, there is no action plan at the continental level. However, the African Centres for Disease Control and Prevention have set up the AMR Surveillance Network (AMRSNET). The objectives of this network are to control the emergence and transmission of AMR by encouraging human and animal health professionals to adhere to the guidelines on the prudent use of antibiotics [3].

In Senegal, the response to the AMR is being organized. The country's capacity to contain this scourge has been assessed by the WHO within the framework of the International Health Regulations. This evaluation revealed the irrational use of antibiotics. The main recommendations are the development of a mul- 
ti-sectoral action plan on AMR, the conduct of surveys and the sensitization of health professionals on the use of antibiotics [15].

Community pharmacists are among the most accessible health professionals [10]. As such, they can play a special role in reducing antibiotic resistance [16]. They are recognized as drug experts. Thus, they can inform patients and prescribers about the rational use of antibiotics [10]. Given their role as communicators advocated in the concept of "seven-star pharmacist" [17], they can participate in the promotion of health by raising awareness about healthy lifestyles such as hand washing and vaccination [10]. However, the knowledge and skills of community pharmacists about antibiotics use should be strengthened so that they can fully fulfill these functions. For this purpose, studies are necessary to identify the shortcomings and therefore the training and awareness areas. However, in Senegal, any study has not been conducted to determine the level of understanding of pharmacists about antibiotic use and its implications for public health. Our goal was to assess the community pharmacists' knowledge, practices and perceptions about antibiotic use and resistance.

\section{Method}

\subsection{Study Settings}

The study took place in community pharmacies located in the departments of Guediawaye and Pikine. The latter is in the suburbs of the Senegalese capital, Dakar. In 2017, their population was estimated at 370,860 and 1,317,123 inhabitants, respectively [18]. These two departments are characterized by low-coverage sewerage networks [19].

\subsection{Type and Period of Study}

This study was cross-sectional. Data were collected from November 15, 2017 to February 15, 2018.

\subsection{Study Population}

The study population consisted of all community pharmacists practicing in the departments of Guediawaye and Pikine.

\subsection{Sampling}

\subsubsection{Sample Size}

We obtained from the Senegal National Order of Pharmacists the list of community pharmacies located in the two departments. According to this list, the number of pharmacies was 141 including 78 in Pikine and 63 in Guediawaye. A total of 121 community pharmacies were physically located. In each pharmacy, we planned to include one pharmacist.

\subsubsection{Inclusion Criteria}

Eligible participants were those who hold a doctoral degree in pharmacy (Pharm. 
D.) and final-year pharmacy students (fifth-year and sixth-year pharmacy students).

\subsubsection{Non-Inclusion Criteria}

Eligible participants whose pharmacies were not physically identified and those who declined to participate in the survey were not included.

\subsubsection{Sampling Procedure}

We included one pharmacist found in the pharmacy on the day of the survey. The participation was voluntary. This choice can be explained by the fact that it is rare to find two pharmacists who work at the same time in a pharmacy. In this study, when there were two or more pharmacists, the most available was included.

\subsection{Collection of Data}

\subsubsection{Collection Tool}

The survey tool was a questionnaire which was developed, on the occasion of this study, by two co-authors. They are academia and have a great experience in community pharmacy practice. All the co-authors reviewed and commented on the questionnaire both in substance and form. They have a great experience in conducting epidemiological studies. The tool was previously tested on ten community pharmacists practicing in the department of Dakar. The pre-test allowed us to identify ambiguous questions. It was readjusted based on comments from the pre-test. We have reformulated or deleted some questions. The final version consisted of seven sections.

The first was related to socio-demographic characteristics. It included six questions: age, sex, marital status, professional status, number of years of experience and location of the pharmacy.

The second section consisted of fifteen questions. It assessed pharmacists' knowledge about antibiotic indications, causes of antibiotic resistance and antibiotics that should be used with caution (critically important antibiotics for human medicine and antibiotics with high potential to select resistance). Response modalities were "true", "false" and "don't know" except for the question on the causes of resistance. We used a multiple choice question. Eight items were proposed. They were all true.

The third section identified pharmacists' sources of information about antibiotic use and resistance. A semi open question was asked.

The practices were collected in the fourth section through four questions: non-prescription dispensing practice, collaboration with prescribers, patientpharmacist communication and communication between pharmacist and pharmacy staff. Response options were "never", "rarely", "occasionally", "often" and "always".

Perceptions were collected in the fifth section using four questions. Pharmacists were invited to give their perceptions about the level of antibiotic consumption in the population, the quality of antibiotic prescriptions, the influence of 
medical representatives and patients on dispensing practices.

The response modalities were "strongly disagree", "disagree", "neutral", "agree" and "strongly agree".

Pharmacists' willingness to undergo training on antibiotic use and resistance was also collected in the last and seventh section. Only one question was asked. The response options were "yes" or "no".

\subsubsection{Collection Method}

We used a self-administered questionnaire. The interviewer was a sixth-year pharmacy student and was trained on the rationale, objectives and methodology of the study. The questionnaire was given to each participant. Then, an appointment was set to collect it within two weeks. The interviewer was able to contact the supervisor at any time to resolve some difficulties encountered in the field.

\subsection{Data Entry and Analysis}

The data were entered using Microsoft Excel 2010. They were analyzed using Epi Info 7. The analysis was descriptive. Variables were expressed as number (n) and percentage (\%).

\subsection{Ethical Considerations}

Our study was observational. It did not involve collection on human or animal tissues. It had no impact on the environment. The data collection method was not binding for the participant since the participant self-administered the questionnaire. The interviewer was provided with an information letter explaining the rationale, objectives and expected results of the study. Free and informed consent was collected from each pharmacist prior to participating in the study. The participant was notified of the possibility of withdrawing from the study at any time without to have the need to explain the reason. The data were collected anonymously and confidentially.

\section{Results}

\subsection{Response Rates}

A total of 121 community pharmacists were contacted. Among them, 94\% (114/121) agreed to participate in the survey. Then 91 questionnaires were returned and completely filled. The response rate was $75 \%$ (91/121).

\subsection{Socio-Demographic Characteristics}

Most (37\%) of the participants belonged to the age group [20 - 29] years. They were male and married in $69 \%$ and $56 \%$ of cases, respectively. Titular pharmacists represented $47 \%$. About $50 \%$ of pharmacists had professional experience of 5 years or more. Seven pharmacists out of ten $(70 \%)$ were practicing in the department of Pikine (Table 1). 
Table 1. Community pharmacists' socio-demographic characteristics, Guediawaye and Pikine, Senegal, November 15, 2017-February 15, 2018 ( $\mathrm{n}=91)$.

\begin{tabular}{|c|c|c|}
\hline Socio-démographic charasteristics & $\mathrm{n}$ & $\%$ \\
\hline \multicolumn{3}{|l|}{ Age group (years) } \\
\hline [20 - 29] & 34 & 37 \\
\hline [30 - 39] & 19 & 21 \\
\hline$[40-49]$ & 18 & 20 \\
\hline [50 - 59] & 17 & 19 \\
\hline$\geq 60$ & 3 & 3 \\
\hline \multicolumn{3}{|l|}{ Sex } \\
\hline Male & 63 & 69 \\
\hline Female & 28 & 31 \\
\hline \multicolumn{3}{|l|}{ Marital status } \\
\hline Married & 51 & 56 \\
\hline Unmarried & 40 & 44 \\
\hline \multicolumn{3}{|l|}{ Professionnalstatus } \\
\hline Tutilarpharmacist & 43 & 47 \\
\hline Assistant pharmacist, Pharm. D & 31 & 34 \\
\hline Fifth-year pharmacy student & 7 & 8 \\
\hline Sixth-year pharmacy student & 10 & 11 \\
\hline \multicolumn{3}{|l|}{ Number of years of experience } \\
\hline$<2$ & 22 & 24 \\
\hline$[2-5]$ & 24 & 26 \\
\hline$[5-10]$ & 15 & 16 \\
\hline$[10-15]$ & 9 & 10 \\
\hline$\geq 15$ & 21 & 23 \\
\hline \multicolumn{3}{|l|}{ Department } \\
\hline Guediawaye & 27 & 30 \\
\hline Pikine & 64 & 70 \\
\hline
\end{tabular}

\subsection{Knowledge}

Most pharmacists incorrectly believed that antibiotics are always effective against sore throat (64.8\%), bronchitis (51.6\%), paronychia (72.5\%) and dental caries (65.9\%). This misconception was also found in one pharmacist out of four for nasopharyngitis (26.4\%), sinusitis (24.2\%) and diarrhea (23.1\%). However, almost all pharmacists recognized that antibiotics are not effective against flu (94.5\%) (Table 2).

In addition, the majority of participants were aware that self-medication (96.7\%), poor patient compliance (94.5\%), inappropriateantibiotic prescribing (85.7\%) and inappropriate antibiotic dispensing (79.1\%) are risk factors for 
Table 2. Community pharmacists' knowledge about antibiotic use and resistance, Guediawaye and Pikine, Senegal, November 15, 2017-February 15, $2018(\mathrm{n}=91)$.

\begin{tabular}{ccc}
\hline Questions & $\mathrm{n}$ & $\%$ \\
\hline 1) Antibiotics are always effective against sore throat & & \\
True & 59 & 64.8 \\
False & 30 & 33 \\
Don't know & 2 & 2.2
\end{tabular}

2) Antibiotics are always effective against nasopharyngitis

$\begin{array}{ccc}\text { True } & 24 & 26.4 \\ \text { False } & 55 & 60.4 \\ \text { Don't know } & 12 & 13.2\end{array}$

3) Antibiotics are always effective against sinusitis

$\begin{array}{ccc}\text { True } & 22 & 24.2 \\ \text { False } & 55 & 60.4 \\ \text { Don't know } & 14 & 15.4\end{array}$

4) Antibiotics are always effective against bronchitis

$\begin{array}{ccc}\text { True } & 47 & 51.6 \\ \text { False } & 30 & 33 \\ \text { Don't know } & 14 & 15.4\end{array}$

5) Antibiotics are always effective against flu

$\begin{array}{ccc}\text { True } & 4 & 4.4 \\ \text { False } & 86 & 94.5 \\ \text { Don't know } & 1 & 1.1\end{array}$

6) Antibiotics are always effective against diarrhea

$\begin{array}{ccc}\text { True } & 21 & 23.1 \\ \text { False } & 62 & 68.1 \\ \text { Don't know } & 8 & 8.8\end{array}$

7) Antibiotics are always effective against dental caries

$\begin{array}{ccc}\text { True } & 60 & 65.9 \\ \text { False } & 21 & 23.1 \\ \text { Don't know } & 10 & 11\end{array}$

8) Antibiotics are always effective against paronychia

$\begin{array}{ccc}\text { True } & 66 & 72.5 \\ \text { False } & 18 & 19.8 \\ \text { Don't know } & 7 & 7.7\end{array}$

9) The causes of antibiotic resistance:

9.1) Self-medication

$\begin{array}{ccc}\text { True } & 88 & 96.7 \\ \text { False } & 2 & 2.2 \\ \text { Don't know } & 1 & 1.1\end{array}$




\section{Continued}

9.2) Poor patient compliance

True
False

Don't know

9.3) Inappropriate antibiotic prescribing

$\begin{array}{ccc}\text { True } & 78 & 85.7 \\ \text { False } & 6 & 6.6 \\ \text { Don't know } & 7 & 7.7\end{array}$

9.4) Inappropriate antibiotic dispensing

$\begin{array}{ccc}\text { True } & 72 & 79.1 \\ \text { False } & 8 & 8.8 \\ \text { Don't know } & 11 & 12.1 \\ \text { Questions } & \mathrm{n} & \%\end{array}$

9.5) Irrational use of antibiotics in veterinary medicine

$\begin{array}{ccc}\text { True } & 30 & 33 \\ \text { False } & 18 & 19.8 \\ \text { Don't know } & 43 & 47.3\end{array}$

9.6) Lack of clinical guidelines

$\begin{array}{ccc}\text { True } & 41 & 45.1 \\ \text { False } & 23 & 25.3 \\ \text { Don't know } & 27 & 29.7\end{array}$

9.7) Poor hand hygiene

$\begin{array}{ccc}\text { True } & 9 & 9.9 \\ \text { False } & 63 & 69.2 \\ \text { Don't know } & 19 & 20.9\end{array}$

9.8) Lack of immunization

$\begin{array}{ccc}\text { True } & 6 & 6.6 \\ \text { False } & 63 & 69.2 \\ \text { Don't know } & 22 & 24.2\end{array}$

10) Antibiotic resistance that occurs in a person represents a threat to population health

$\begin{array}{ccc}\text { True } & 86 & 94.5 \\ \text { False } & 4 & 4.4 \\ \text { Don't know } & 1 & 1.1\end{array}$

11) Antibiotic resistance occurs only in hospitalized patients

$\begin{array}{ccc}\text { True } & 5 & 5.5 \\ \text { False } & 82 & 90.1 \\ \text { Don't know } & 4 & 4.4\end{array}$

12) Of the following antibiotics, three are among the classes that are almost the only ones to treat serious human infections. Which ?

Thirdgeneration cephalosporins*

69

75.8 


\section{Continued}

$\begin{array}{ccc}\text { Macrolides }^{*} & 54 & 59.3 \\ \text { Penicillins } & 50 & 54.9 \\ \text { Quinolones }^{*} & 49 & 53.8 \\ \text { Sulfonamideantibiotics } & 26 & 28.6 \\ \text { Tetracyclines } & 9 & 9.9\end{array}$

13) Cephalosporins are particularly prone to promote antibiotic resistance

$\begin{array}{ccc}\text { True } & 16 & 17.6 \\ \text { False } & 39 & 42.9 \\ \text { Don't know } & 36 & 39.6\end{array}$

14) Amoxicillin/Acid clavulanic are particularly prone to promote bacterial resistance

$\begin{array}{ccc}\text { True } & 10 & 11 \\ \text { False } & 60 & 65.9 \\ \text { Don't know } & 21 & 23.1\end{array}$

15) Fluoroquinolones are particularly prone to promote antibiotic resistance

$\begin{array}{ccc}\text { True } & 10 & 11 \\ \text { False } & 33 & 36.3 \\ \text { Don't know } & 48 & 52.7\end{array}$

${ }^{*}$ Correct responses.

antibiotic resistance. In parallel, $33 \%$ and $45.1 \%$ of pharmacists agreed that the irrational use of antibiotics in animals and the lack of clinical guidelines also contribute to antibiotic resistance. However, only $9.9 \%$ and $6.6 \%$ knew that poor hand hygiene and lack of vaccination can lead to antibiotic resistance, respectively (Table 2).

In total, only $2.2 \%$ of pharmacists could identify all causes of antibiotic resistance which were listed in the questionnaire (Table 2).

Nearly $95 \%$ of pharmacists were aware that antibiotic resistance which occurs in a person represents a threat to population health (Table 2).

Only $5.5 \%$ of participants incorrectly believed that antibiotic resistance only occurs in hospitalized patients (Table 2).

A quarter (25.2\%) of pharmacists was aware that third-generation cephalosporins, quinolones and macrolides are among the only classes of antibiotics that treat serious human infections (Table 2).

A small proportion of pharmacists were aware that third generation cephalosporins (17.6\%), amoxicillin/clavulanic acid (11\%) and fluoroquinolones (11\%) are particularly prone to promote antibiotic resistance (Table 2).

\subsection{Sources of Information}

The three most cited sources of information were the Internet (65.9\%), pharmacists (63.7\%) and books (53.8\%). They are followed by leaflet drug (35.5\%), 
physicians (29.7\%) and the Ministry of Health (17.6\%). The lowest were TV $(9.9 \%)$, radio $(7.7 \%)$ and training workshops (3.3\%) (Table 3$)$.

\subsection{Practices}

The majority (96.7\%) of pharmacists said they dispense antibiotics without a prescription. Among them, $17.6 \%$ said they often practiced this form of dispensing.

At the same time, $90.2 \%$ stated that they contact the prescribers if they doubt on the reliability of an antibiotic prescription. However, only $16.5 \%$ always do it.

Finally, $27.5 \%$ and $54.9 \%$ of pharmacists indicated that they always educate pharmacy staff and patients about the rational use of antibiotics, respectively (Table 4).

\subsection{Perceptions}

Nine pharmacists out of ten estimated that antibiotic use was high in their area while $29.7 \%$ thought that some antibiotic prescriptions are inappropriate.

Nearly half (47.3\%) claimed that medical representatives put pressure on them to sell their drugs.

According to $89.1 \%$ of pharmacists, there is an excessive demand for antibiotics by the population (Table 5 ).

\subsection{Motivation to Receive Training on Antibiotic Use and Resistance}

Almost all the pharmacists (93.4\%) were willing to receive training on antibiotic use and resistance.

\section{Discussion}

\subsection{Knowledge}

This study showed that some pharmacists incorrectly thought that antibiotics are always effective against respiratory infections such as sore throat, nasopharyngitis, sinusitis and bronchitis. However, in most cases, these infections are of viral origin and self-limiting [20]. Therefore, antibiotic therapy should not be routinely prescribed for these infections [20]. However, in the United States, nearly $68 \%$ of patients with respiratory infections are unnecessarily treated with antibiotics [9]. This situation could lead to resistance. The establishment of rapid diagnostic tests in pharmacies could be a solution. When the result is positive, pharmacists could refer the patient to prescribers. Conversely, when it is negative, they could advise patients to drink plenty of water, rest and take analgesics to relieve symptoms [21].

Nearly $70 \%$ of diarrhea episodes are caused by viruses [9]. Yet, in this study, some pharmacists incorrectly felt that antibiotics are always effective against diarrhea. In middle-income countries, nearly 500 million antibiotic courses are used each year for the management of diarrhea [9]. Solutions exist to limit the 
Table 3. Community pharmacists' sources of information on antibiotic use and resistance, Guediawaye and Pikine, Senegal, November 15, 2017-February 15, 2018 (n = 91).

\begin{tabular}{ccc}
\hline Sources of information & $\mathrm{n}$ & $\%$ \\
\hline Internet & 60 & 65.9 \\
Pharmacists & 58 & 63.7 \\
Books & 49 & 53.8 \\
Leaflet drug & 32 & 35.2 \\
Physicians & 27 & 29.7 \\
Ministry of health & 16 & 17.6 \\
TV & 9 & 9.9 \\
Radio & 7 & 7.7 \\
Training workshops & 3 & 3.3 \\
\hline
\end{tabular}

Table 4. Community pharmacists' practices about the use of antibiotics, Guediawaye and Pikine, Senegal, November 15, 2017-February 15, $2018(\mathrm{n}=91)$.

\begin{tabular}{|c|c|c|c|c|c|}
\hline Statements & $\begin{array}{c}1^{*} \\
\mathrm{n}(\%)\end{array}$ & $\begin{array}{c}2^{*} \\
\mathrm{n}(\%)\end{array}$ & $\begin{array}{c}3^{*} \\
\mathrm{n}(\%)\end{array}$ & $\begin{array}{c}4^{*} \\
\mathrm{n}(\%)\end{array}$ & $\begin{array}{c}5^{\star} \\
\mathrm{n}(\%)\end{array}$ \\
\hline 1) I dispense antibiotics without a prescription & $\begin{array}{c}3 \\
(3.3 \%)\end{array}$ & $\begin{array}{c}21 \\
(23.1 \%)\end{array}$ & $\begin{array}{c}51 \\
(56 \%)\end{array}$ & $\begin{array}{c}16 \\
(17.6 \%)\end{array}$ & $\begin{array}{c}0 \\
0(\%)\end{array}$ \\
\hline $\begin{array}{l}\text { 2) I communicate with prescribers if I am unsure } \\
\text { about the appropriateness of an antibiotic } \\
\text { prescription }\end{array}$ & $\begin{array}{c}9 \\
(9.9 \%)\end{array}$ & $\begin{array}{c}21 \\
(23.1 \%)\end{array}$ & $\begin{array}{c}16 \\
(17.6 \%)\end{array}$ & $\begin{array}{c}30 \\
(33 \%)\end{array}$ & $\begin{array}{c}15 \\
(16.5 \%)\end{array}$ \\
\hline $\begin{array}{l}\text { 3) I educate pharmacy staff on the importance of } \\
\text { rational use of antibiotics }\end{array}$ & $\begin{array}{c}9 \\
(9.9 \%)\end{array}$ & $\begin{array}{c}11 \\
(12.1 \%)\end{array}$ & $\begin{array}{c}14 \\
\left(15.4 \%^{\circ}\right.\end{array}$ & $\begin{array}{c}32 \\
(35.2 \%)\end{array}$ & $\begin{array}{c}25 \\
(27.5 \%)\end{array}$ \\
\hline $\begin{array}{l}\text { 4) I educate patients on the importance of rational } \\
\text { use of antibiotics }\end{array}$ & $\begin{array}{c}0 \\
(0 \%)\end{array}$ & $\begin{array}{c}2 \\
(2.2 \%)\end{array}$ & $\begin{array}{c}6 \\
(6.6 \%)\end{array}$ & $\begin{array}{c}33 \\
(36.3 \%)\end{array}$ & $\begin{array}{c}50 \\
(54.9 \%)\end{array}$ \\
\hline
\end{tabular}

$1^{*}=$ Never; $2^{\star}=$ Rarely; $3^{*}=$ Occasionally; $4^{*}=$ Often; $5^{*}=$ Always.

Table 5. Community pharmacists' perceptions about the use of antibiotics, Guediawaye and Pikine, Senegal, November 15, 2017-February 15, $2018(\mathrm{n}=91)$.

\begin{tabular}{|c|c|c|c|c|c|}
\hline Statements & $\begin{array}{c}1^{*} \\
\mathrm{n}(\%)\end{array}$ & $\begin{array}{c}2^{*} \\
\mathrm{n}(\%)\end{array}$ & $\begin{array}{c}3^{*} \\
\mathrm{n}(\%)\end{array}$ & $\begin{array}{c}4^{*} \\
\mathrm{n}(\%)\end{array}$ & $\begin{array}{c}5^{*} \\
\mathrm{n}(\%)\end{array}$ \\
\hline 1) Antibiotic consumption is high in your area & $\begin{array}{c}1 \\
(1.1 \%)\end{array}$ & $\begin{array}{c}2 \\
(2.2 \%)\end{array}$ & $\begin{array}{c}4 \\
(4.4 \%)\end{array}$ & $\begin{array}{c}52 \\
(57.1 \%)\end{array}$ & $\begin{array}{c}32 \\
(35.2 \%)\end{array}$ \\
\hline $\begin{array}{l}\text { 2) Some antibiotic prescriptions that you receive } \\
\text { are inappropriate }\end{array}$ & $\begin{array}{c}11 \\
(12.1 \%)\end{array}$ & $\begin{array}{c}45 \\
(49.5 \%)\end{array}$ & $\begin{array}{c}8 \\
(8.8 \%)\end{array}$ & $\begin{array}{c}22 \\
(24.2 \%)\end{array}$ & $\begin{array}{c}5 \\
(5.5 \%)\end{array}$ \\
\hline $\begin{array}{l}\text { 3) Medical representatives exert an influence on } \\
\text { pharmacists for the sale of their products }\end{array}$ & $\begin{array}{c}16 \\
(17.6 \%)\end{array}$ & $\begin{array}{c}27 \\
(29.7 \%)\end{array}$ & $\begin{array}{c}5 \\
\left(5.5 \%^{\circ}\right)\end{array}$ & $\begin{array}{c}26 \\
(28.6 \%)\end{array}$ & $\begin{array}{c}17 \\
(18.7 \%)\end{array}$ \\
\hline $\begin{array}{l}\text { 4) Customers demand excessively antibiotics } \\
\text { without a prescription in community pharmacies }\end{array}$ & $\begin{array}{c}4 \\
(4.4 \%)\end{array}$ & $\begin{array}{c}5 \\
(5.5 \%)\end{array}$ & $\begin{array}{c}1 \\
(1.1 \%)\end{array}$ & $\begin{array}{c}45 \\
(49.5 \%)\end{array}$ & $\begin{array}{c}36 \\
(39.6 \%)\end{array}$ \\
\hline
\end{tabular}

$1^{\star}=$ Strongly disagree; $2^{\star}=$ Disagree; $3^{\star}=$ Neutral; $4^{\star}=$ Agree; $5^{\star}=$ Strongly agree .

overuse of antibiotics [9] [19]. At the political level, it is mainly about improving access to quality water and adequate sanitation [9]. These two strategies could 
reduce the unnecessary consumption of antibiotics by $60 \%$ [9]. On the other hand, there is a need to educate community pharmacists on the importance of advising oral rehydration solutions and zinc for the treatment of diarrhea in children under five [19].

The belief that antibiotics are always effective against dental caries and paronychia was another misconception demonstrated in our study. However, the recommendations do not support the use of antibiotics in these conditions [22] [23]. In oral medicine, antibiotics are reserved for infrequent situations. Oral hygiene is fundamental in the prevention of infections [22]. As for paronychia, antibiotics are not recommended in the inflammatory stage. Antiseptic baths repeated 3 to 4 times a day and dressings are indicated [23].

Health education and disease prevention is a public health goal [17]. Pharmacists play an important role in these interventions given their accessibility. Thus, their awareness about the risk factors for antibiotic resistance is fundamental. In our study, most pharmacists were aware of the relationship between antibiotic resistance and certain practices such as self-medication and treatment non-compliance. It has been established that many patients reuse antibiotics remaining from their previous treatment [10]. This is, moreover, indicative of a non-compliance with treatment. Thus, the pharmacist can play a key role in encouraging patients to return unused antibiotics in order to avoid self-medication [10]. Most of them did not know that the lack of immunization and poor hand hygiene contributed to the emergence of antibiotic resistance. These results corroborate those found in a study conducted among community pharmacists in Brazil [24]. Our study showed that it is important to educate community pharmacists on the importance of immunization and hand hygiene in the prevention and control of infections [10]. Thus, they will be able to promote these two strategies among the populations. Immunization protects against infectious diseases including viral infections in which antibiotics are unnecessarily prescribed [10]. In resource-poor countries, hand washing has been shown to reduce diarrhea by $47 \%$ [4]. It also has beneficial effects on the prevention of community respiratory infections [4]. These strategies would therefore make it possible to avoid the unnecessary consumption of antibiotics and consequently resistance.

In addition, few pharmacists admitted that the irrational use of antibiotics in veterinary medicine is a risk factor for antibiotic resistance. Yet this link is widely proven in the literature [9] [16]. Failure to understand this link could be a barrier to future and imperative collaboration between pharmacists and animal health professionals in the fight against antibiotic resistance. Promoting the "One Health" approach should be an opportunity not only to make pharmacists aware of the link between human health, animal health and environment, but also to encourage them to collaborate with all stakeholders.

Antibiotic resistance is a threat to global health and health system. The use of an antibiotic in a single patient is enough to create antibiotic resistance that can spread to others [25]. In this study, almost all the pharmacists were aware of this evidence. This result is better than that found in Sri Lanka [26]. The study con- 
ducted in this country showed that $63 \%$ of final-year pharmacy students knew that resistant bacteria can be transmitted from one person to another [26]. In Dakar, the average household size is 7 people per household. This shows that promiscuity is a major concern in the Senegalese capital and may be a factor favoring transmission [19]. The result of our study is encouraging and should allow pharmacists to lead each patient to respect the method of taking antibiotics. They can also participate in health promotion activities to limit the risk of transmission. For example, in Australia, community pharmacists are involved in sensitizing populations on the importance of isolating infected patients. Similarly, in Great Britain, they provide advice on sexual health [10].

In the past, antibiotic-resistant infections typically occurred in hospitals. However, they are becoming more common in community settings [1] [9]. In our study, the majority of participants recognized this situation. Pharmacies are well established in the community. This places pharmacists in a privileged position to contribute to the prevention of resistance in outpatients and the general population.

The phenomenon of antibiotic resistance is progressing. At the same time, few new antibiotics are being developed [13] [16]. Thus, the WHO recommends prudent use of currently available antibiotics including those critically important for human medicine. According to the WHO, these are almost the only ones to treat serious human infections [13]. These include third-generation cephalosporins, quinolones and macrolides. In our study, few pharmacists were able to cite them.

On the other hand, the use of certain classes of antibiotics can lead to antibiotic selection pressure and antibiotic resistance [14]. These include third-generation cephalosporins, fluoroquinolones and amoxicillin/clavulanic acid [14]. However, a small proportion of community pharmacists were able to recognize these three classes of antibiotics as likely to generate resistance. These results would highlight two shortcomings. First, they assume that pharmacists do not get enough information about which antibiotic families should be used with caution. Second, pharmacists would not research enough to keep up with the news on antibiotic resistance. Yet research is a new activity advocated in the concept of "seven-star pharmacist". According to this concept, the community pharmacist must be able to use proven facts effectively to provide advice on the rational use of medicines [10].

\subsection{Sources of Information}

The main sources of information for pharmacists on antibiotic use and resistance are internet, pharmacists, books and drug leaflets. These results revealed two lessons. On the one hand, the Ministry of Health does not appear as one of the main sources of information for pharmacists since it was mentioned in only $17.6 \%$ of cases. On the other hand, pharmacists do not have access to independent information when they try to improve their knowledge using drug leaflets. 
Faced with this situation, three actions should be carried out. First, the Ministry of Health should collaborate with the Senegal National Order of Pharmacists to define the conditions for the development and transmission of periodic newsletters on antibiotic use and resistance. Second, the creation of a pharmaceutical information center could enable pharmacists to have access to updated, independent and reliable information. Finally, a website dedicated exclusively to antibiotic resistance should be set up.

\subsection{Practices}

In many African countries, antibiotics can be sold over-the-counter [9]. In this study, almost all the participants dispensed antibiotics without a prescription. In countries such as Ethiopia and Pakistan, this practice was found in $37 \%$ and $24.8 \%$ of pharmacists, respectively [27] [28]. A study conducted in Albania showed that some pharmacists stated that if they refused to dispense antibiotics without a prescription, patients could get them at another pharmacy [7]. This dispensing practice could also be explained by the weakness of the regulation on the sale of medicines in developing countries [9]. It contributes to the emergence of antibiotic resistance. Therefore, there is an urgent need to educate pharmacists about the harmful effects of this practice, strengthen the regulation of the pharmaceutical sector and discourage people from demanding for antibiotics without a prescription.

Communication between pharmacists and other health professionals such as prescribers is essential in resolving or preventing drug-related problems [10]. In this study, about $16.5 \%$ of pharmacists said they always contact prescribers when they doubt on the reliability of an antibiotic prescription. This result is better than that found in Pakistan [28]. The introduction of an antimicrobial stewardship program extended to community pharmacists would be essential [27]. Thus, this program will be an opportunity to create and strengthen this collaboration since the fight against antibiotic resistance requires an exchange of information between all stakeholders. Pharmacists, as drug experts, could play a role in advising prescribers on the appropriate use of antibiotics [10].

The community pharmacist must assume some responsibility in sharing information with his colleagues in the pharmacy. In this study, only $27.5 \%$ said they were always making their colleagues aware of the importance of the rational use of antibiotics. However, several participants are titular pharmacists or have a professional experience of more than 10 years. This asset should enable them to discuss with assistants, who are usually final-year pharmacy students, about different aspects of antibiotic use.

The pharmacist represents the entry gate into the health system because of its accessibility [10]. The pharmacist is also the last health professional to whom the patient talks before taking his treatment [29]. This dual position should represent an important opportunity in order to make patients aware about the safe and effective use of antibiotics [17]. In our study, more than half of participants said 
they always communicate with patients about the importance of rational use of antibiotics. In Ethiopia, this indicator was 24.2\% [27]. However, to assume this role of communicator and collaborator, pharmacists should acquire oral, non-oral, listening and writing skills [17].

\subsection{Perceptions}

In this study, about one third and half of the pharmacists thought that some antibiotic prescriptions were inadequate and the population was overly demanding for antibiotics, respectively. Similarly, several participants admitted to being pressured by medical representatives. In developing countries, inappropriate prescriptions, commercial pressure and patient demand for antibiotics have been shown to negatively influence pharmacists' practices [26]. These different perceptions expressed by the participants in our study would reflect the overconsumption of antibiotics which is demonstrated in a recent study. This increase is most noticeable in developing countries [30]. The pharmacists surveyed in our study seem to confirm this level of consumption, since among them $86.3 \%$ suggested that antibiotic consumption is high in their respective zones. In West Africa, this situation could be explained by the endemicity of respiratory infections, bacterial meningitis, diarrhea and other infectious diseases [4]. Two actions should be taken in order to tackle this concern. On the one hand, further studies would be needed to describe prescribing practices and the behavior of the general public regarding the use of antibiotics. On the other hand, the regulation of medical representatives' profession should be strengthened.

\subsection{Motivation to Receive Training on Antibiotic Use and Resistance}

Health faces many challenges including antibiotic resistance. It is in this context that the role of the pharmacist has shifted from that of preparer and dispenser to that of "drug therapy manager" [17]. This new role implies that the pharmacist acquires new knowledge. In this study, participants seem to realize not only the urgent need to update their knowledge acquired in an institute but also their role in the fight against antibiotic resistance. Indeed, most of them were willing to receive training on antibiotic use and resistance. This motivation to learn is in line with the concept of "seven-star pharmacists" who recommend that pharmacists learn throughout life [17]. For this purpose, they can attend scientific congresses such as the medical and pharmaceutical days that take place at the Faculty of Medicine, Pharmacy and Odontology of University Cheikh Anta Diop. The Senegal' Ministry of Health should also initiate a periodic training program for community pharmacists on antibiotic use and its challenges.

\subsection{Limits}

Our study has some limits. First, it is not representative of all community pharmacists in Senegal because it has been conducted in two departments. These are 
in the capital. So the situation could be different in rural areas. Then, the data collection method was self-administration. Some participants may be tempted to answer questions after they have documented themselves. However, to the best of our knowledge, this study is the first in Senegal. It provides important data on the stakes of the fight against antibiotic resistance.

\section{Conclusion}

This study showed that pharmacists were aware that antibiotic resistance is a threat to population health. It has revealed misconceptions about the use of antibiotics against infections commonly found in the general population. Similarly, most pharmacists were unaware that the lack of vaccination and poor hand hygiene contributed to the emergence of antibiotic resistance. They also misunderstood the notion of critically important antibiotics and those with high potential to select resistance. The dispensing of antibiotics without a medical prescription, and the weakness of the collaboration with the prescribers are practices highlighted in this study. In view of these results, the sensitization of community pharmacists would be essential. Further studies would be needed to deeply describe the practices of community pharmacists regarding antibiotic use.

\section{Funding}

This research received no external funding.

\section{Acknowledgements}

We are very grateful to the community pharmacists who agreed to participate in this study.

\section{Conflicts of Interest}

The authors do not declare any conflict of interest.

\section{References}

[1] Centers for Diseases Control and Prevention (2013) Antibiotic Resistance Threats in the United States. https://www.cdc.gov/drugresistance/pdf/ar-threats-2013-508.pdf

[2] World Health Organisation (2014) Antimicrobial Resistance. Global Report on Surveillance. Geneva.

http://apps.who.int/iris/bitstream/handle/10665/112642/9789241564748_eng.pdf;jse ssionid=5290CC8F73C7B46FDD0DD9FB65AC549F? sequence $=1$

[3] Africa Centres for Diseases Control and Prevention (2018) Cadre des CDC africains pour la resistance antimicrobienne 2018-2023. Réseau de surveillance RAM (AMRSNET). Africa CDC, Addis Ababa.

http://www.africacdc.org/resources/strategic-framework/strategic-framework/africa -cdc-amr-framework-french/detail

[4] Ouedraogo, A.S., Jean Pierre, H., Bañuls, A.L., Ouédraogo, R. and Godreuil, S. (2017) Émergence et diffusion de la résistance aux antibiotiques en Afrique de l'Ouest: Facteurs favorisants et évaluation de la menace. Médecine et Santé Tropicales, 
27, 147-154. https://doi.org/10.1684/mst.2017.0678

[5] Sambe-Ba, B., Seck, A., Wane, A.A., Fall-Niang, N.K. and Gassama-Sow, A. (2013) Sensibilité aux antibiotiques et supports génétiques de la résistance des souches de Shigella flexneri isolées à Dakar de 2001 à 2010. Bulletin de la Société de Pathologie Exotique, 106, 89-94. https://doi.org/10.1007/s13149-013-0283-Z

[6] Zaman, S.B., Hussain, M.A., Nye, R., Mehta, V., Mamun, K.T., et al. (2017) A Review on Antibiotic Resistance: Alarm Bells Are Ringing. Cureus, 9, e1403. https://doi.org/10.7759/cureus.1403

[7] Hoxha, I., Malaj, A., Kraja, B., Bino, S., Oluka, M., et al. (2018) Are Pharmacists' Good Knowledge and Awareness on Antibiotics Taken for Granted? The Situation in Albania and Future Implications across Countries. Journal of Global Antimicrobial Resistance, 13, 240-245. https://doi.org/10.1016/j.jgar.2018.01.019

[8] World Bank Group (2017) Drug-Resistant Infections: A Threat to Our Economic Future. Final Report, WBG, Washington DC.

http://documents.worldbank.org/curated/en/323311493396993758/pdf/114679-RE VISED-v2-Drug-Resistant-Infections-Final-Report.pdf

[9] O’Neill, J. (2016) Tackling Drug-Resistant Infections Globally: Final Report and Recommendations. Review on Antimicrobial Resistance. Wellcome Trust and HM Government.

https://amr-review.org/sites/default/files/160525_Final\%20paper_with\%20cover.pdf

[10] International Pharmaceutical Federation (2015) Fighting Antimicrobial Resistance. The Contribution of Pharmacists. FIP Policy Analyst \& Project Coordinator, FIP General Secretary \& CEO, The Hague.

http://www.fip.org/files/fip/publications/2015-11-Fighting-antimicrobial-resistance. pdf

[11] Organisation Mondiale de la Santé (2016) Plan D’action Mondial Pour Combattre la Résistance Aux Antimicrobiens. OMS, Généve. http://apps.who.int/iris/bitstream/handle/10665/249548/9789242509762fre.pdf;jsess ionid=6BA7B094CA69BC758FC52F00A7E179E0? sequence $=1$

[12] Commission européenne (2017) Communication de la Commission au Conseil et au Parlement Européen. Plan d'action européen fondé sur le principe Une seule santé pour combattre la résistance aux antimicrobiens. COM/2017/0339 final. Commission européenne, Bruxelles.

https://eur-lex.europa.eu/legal-content/FR/TXT/PDF/?uri=CELEX:52017DC0339\&f rom $=\mathrm{FR}$

[13] Organisation Mondiale de la Santé (2016) Liste OMS des antibiotiques d'importance critique pour la médecine humaine (liste CIA). OMS, Généve. http://www.who.int/foodsafety/publications/CIAflyer_fr.pdf

[14] Agence nationale de sécurité du médicament et des produits de santé (2016) Liste des antibiotiques critiques. Actualisation 2015. Rapport. ANSM, Saint-Denis. https://ansm.sante.fr/var/ansm_site/storage/original/application/91feadb5d6bf2cbc 3dbe9de9ca7bec06.pdf

[15] Organisation Mondiale de la santé (2017) Évaluation Externe Conjointe des Principales Capacités RSI de la Republique du Senegal; Rapport de Mission: 28 Novembre-2 Décembre 2016; OMS, Généve. http://apps.who.int/iris/bitstream/handle/10665/255765/WHO-WHE-CPI-2017.31fre.pdf?sequence $=1$

[16] Mason, T., Trochez, C., Thomas, R., Babar, M., Hesso, I., et al. (2018) Knowledge and Awareness of the General Public and Perception of Pharmacists about Antibi- 
otic Resistance. BMC Public Health, 18, 711.

https://doi.org/10.1186/s12889-018-5614-3

[17] Organisation Mondiale de la Santé. Fédération internationale pharmaceutique (2006) In Elargir la Pratique Pharmaceutique. Recentrer les Soins sur les Patients. OMS, Généve. http://apps.who.int/medicinedocs/documents/s16219f/s16219f.pdf

[18] Agence Nationale de la Statistique et de la Démographie (2013) Projection de la Population de la Region de Dakar, 2013-2025. ANSD, Dakar.

http://www.ansd.sn/ressources/publications/indicateurs/Projections-demographiqu es-2013-2025+.htm

[19] Agence Nationale de la Statistique et de la Démographie et Fonds des Nations Unies pour l'enfance (2016) MICS V Dakar Enquête par Grappes à Indicateurs Multiples 2015-2016. Rapport Final, ANSD, Dakar.

http://www.ansd.sn/ressources/publications/RAPPORT\%20MICS\%20Urbaine\%20

Dakar\%202015-2016_FINAL\%20novembre_version\%20finale\%20.pdf

[20] Centre for Clinical Practice at NICE (UK) (2008) Respiratory Tract Infections-Antibiotic Prescribing: Prescribing of Antibiotics for Self-Limiting Respiratory Tract Infections in Adults and Children in Primary Care. National Institute for Health and Clinical Excellence, London.

[21] Fleming, N., Barber, S. and Ashiru-Oredope, D. (2011) Pharmacists Have a Critical Role in the Conservation of Effective Antibiotics. The Pharmaceutical Journal, 287, 465.

https://www.pharmaceutical-journal.com/news-and-analysis/pharmacists-have-a-cr itical-role-in-the-conservation-of-effective-antibiotics/11086917.article

[22] Lesclous, P. (2011) Prescription des antibiotiques en pratique bucco-dentaire. Recommandations AFSSAPS 2011. Médecine Buccale Chirurgie Buccale, 17, 334-346. https://doi.org/10.1051/mbcb/2011138

[23] Rockwell, P.G. (2001) Acute and Chronic Paronychia. American Family Physician, 63, 1113-1116.

[24] Del Fiol Fde, S., Barberato-Filho, S., Lopes, L.C., Bergamaschi Cda, C. and Boscariol, R. (2015) Assessment of Brazilian Pharmacists' Knowledge about Antimicrobial Resistance. The Journal of Infection in Developing Countries, 9, 239-243. https://doi.org/10.3855/jidc.4853

[25] World Alliance against Antibiotic Resistance (2017) WAAAR Declaration. Junior Centrale Supelec, Paris. https://waaar.org

[26] Sakeena, M.H.F., Bennett, A.A., Jamshed, S., Mohamed, F., Herath, D.R., et al. (2018) Investigating Knowledge Regarding Antibiotics and Antimicrobial Resistance among Pharmacy Students in Sri Lankan Universities. BMC Infectious Diseases, 18, 209. https://doi.org/10.1186/s12879-018-3107-8

[27] Erku, D.A. (2016) Antimicrobial Stewardship: A Cross-Sectional Survey Assessing the Perceptions and Practices of Community Pharmacists in Ethiopia. Interdisciplinary Perspectives on Infectious Diseases, 2016, Article ID: 5686752. https://doi.org/10.1155/2016/5686752

[28] Sarwar, M.R., Saqib, A., Iftikhar, S. and Sadiq, T. (2018) Knowledge of Community Pharmacists about Antibiotics, and Their Perceptions and Practices Regarding Antimicrobial Stewardship: A Cross-Sectional Study in Punjab, Pakistan. Infection and Drug Resistance, 11, 133-145. https://doi.org/10.2147/IDR.S148102

[29] Pharmaceutical Group of European Union (2017) The Community Pharmacy Contribution to Tackling Antimicrobial Resistance (AMR). PGEU, Brussel.

https://www.pgeu.eu/en/policy/6:antibiotic-resistance.html 
[30] Klein, E.Y., Van Boeckel, T.P., Martinez, E.M., Pant, S., Gandra, S., et al. (2018) Global Increase and Geographic Convergence in Antibiotic Consumption between 2000 and 2015. Proceedings of the National Academy of Sciences of the United States of America, 115, E3463-E3470. https://doi.org/10.1073/pnas.1717295115 